\title{
Human $\beta$-defensin-3 promotes intestinal epithelial cell migration and reduces the development of necrotizing enterocolitis in a neonatal rat model
}

\author{
Qingfeng Sheng ${ }^{1,2}$, Zhibao Lv' ${ }^{1}$, Wei Cai ${ }^{2}$, Huanlei Song ${ }^{2}$, Linxi Qian², Huaibo Mu' ${ }^{1}$ Jingyi Shi' and Xueli Wang ${ }^{3}$
}

BACKGROUND: The aim of this study was to investigate the effects of human $\beta$-defensin-3 (hBD3) on intestinal wound healing and in a neonatal rat model of necrotizing enterocolitis (NEC).

METHODS: Enterocyte migration and proliferation were detected in vitro and in vivo. The role of chemokine receptor CCR6 and its downstream signaling pathway was assessed. Newborn Sprague-Dawley rats were randomly divided into four groups: Control+NS, Control+hBD3, NEC+NS, and NEC+hBD3. Body weight, histological score, survival time, cytokines expression, and mucosal integrity were evaluated.

RESULTS: hBD3 could stimulate enterocyte migration, but not proliferation, both in cultured enterocytes and in the NEC model. Neutralizing antibody and small interfering RNA confirmed this stimulatory effect was mediated by CCR6. Furthermore, hBD3 induced Rho activation, myosin light chain 2 phosphorylation, and F-actin accumulation. The bactericidal activity of hBD3 was maintained throughout a broad $\mathrm{pH}$ range. Strikingly, hBD3 administration decreased the incidence of NEC, increased the survival rate, and reduced the severity of NEC. Moreover, hBD3 reduced the proinflammatory cytokines expression in ileum and serum and preserved the intestinal barrier integrity.

CONCLUSION: This study provided evidence that the antimicrobial peptide hBD3 might participate in intestinal wound healing by promoting enterocyte migration and show beneficial effects on newborn rats with NEC.

N ecrotizing enterocolitis (NEC) is the leading cause of death from gastrointestinal diseases in premature newborns (1). Intestinal barrier dysfunction plays an important role in the pathogenesis of NEC. Impaired healing of the damaged mucosa, including epithelial migration and proliferation, has been observed in human and experimental NEC $(2,3)$.

Human $\beta$-defensin-3 (hBD3, OMIM: 606611), one member of cationic antimicrobial peptides, is inducibly expressed in the epithelium of gut. In addition to the primarily recognized antimicrobial activities, hBD3 also functions as immune modulators linking innate and adaptive immunity $(4,5)$. Analysis of intestinal resections obtained from infants with severe NEC revealed that low defensin mRNA and protein expression (6). Armogida et al. (7) reported that the presence of mediators of the innate immune system in human milk, including hBD3 provided protection for the developing digestive tract of newborns. In addition, defensins induction seemed to be a common and important mechanism of probiotics treatment $(8,9)$. Collectively, these studies suggested an important role of defensins in neonatal mucosal defense and intestinal barrier function.

Previous studies revealed the capacity of hBD3 to chemoattract T lymphocytes and CCR6-transfected human embryonic kidney 293 cells through chemokine receptor CCR6, which is also constitutively expressed on human enterocytes $(10,11)$. Chemokine ligand CCL20, also known as macrophage inflammatory protein-3 $\alpha$, has been shown to be a unique functional ligand for CCR6. The ligand-receptor pair CCL20-CCR6 plays an important role in gut homeostasis (12). Thus, CCR6 seems to be able to act as a receptor for both hBD3 and CCL20. Recently, Hirsch et al. (13) reported that hBD3 expression significantly promoted wound healing in Staphylococcus aureusinfected diabetic wounds which were created on the backs of Yorkshire pigs. However, the effect of hBD3 on intestinal wound healing remains unknown to date.

The aim of the current study was to investigate the effects of hBD3 on wound healing in cultured enterocytes and in a well-established rat model of NEC. In this study, we reported that hBD3 could promote migration, but not proliferation, of human and rat intestinal epithelial cells (IECs). Furthermore, we showed that hBD3 treatment could decrease the incidence and severity of NEC, reduce the expression of inflammatory mediators, and protect the intestinal barrier integrity.

\section{RESULTS}

hBD3 Promotes IEC Migration

Tris-Tricine gel electrophoresis analysis revealed a single band migrating like a $5-\mathrm{kDa}$ polypeptide (Figure 1a). And

'Department of General Surgery, Children's Hospital of Shanghai, Shanghai Jiao Tong University, Shanghai, P. R. China; ${ }^{2}$ Shanghai Key Laboratory of Pediatric Gastroenterology and Nutrition, Shanghai, P. R. China; ${ }^{3}$ Department of Pathology, Children's Hospital of Shanghai, Shanghai Jiao Tong University, Shanghai, P. R. China. Correspondence: Zhibao Lv (Ivzhibao@sohu.com; zhibao-Iv@hotmail.com) 


\section{Articles | shenget al.}
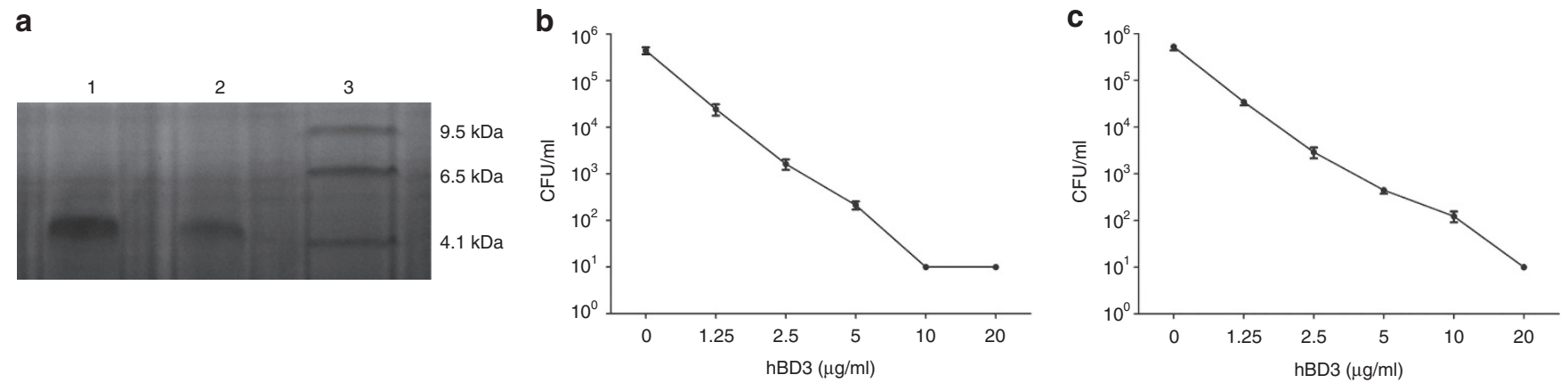

Figure 1. Identification and antimicrobial activity of hBD3. (a) Coomassie-stained 16.5\% Tris-Tricine gel of the recombinant hBD3. Lane 1, 50 ng hBD3; lane 2, $25 \mathrm{ng}$ hBD3; lane 3, protein marker. Bactericidal activities of hBD3 against clinical isolates (b) Escherichia coli and (c) Staphylococcus aureus after $2 \mathrm{~h}$ of incubation in $10 \mathrm{mmol} / \mathrm{l}$ sodium phosphate buffer $(\mathrm{pH}$ 7.4). Data are mean $\pm \mathrm{SD}$ of three independent experiments.

hBD3 exhibited bactericidal activity against clinical isolates Escherichia coli (Figure 1b) and S. aureus (Figure 1c) in a dose-dependent manner.

No significant cytotoxicity of hBD3 against IEC-6 was observed over a broad range of concentrations and incubation periods as shown in Figure 2a. Comparable results were detected in Caco- 2 cells treated with hBD3.

Next, as shown in Figure $\mathbf{2 b}$, cells incubated with hBD3 or CCL20 migrated more than the unstimulated controls, with transforming growth factor- $\beta 1$ (TGF $\beta 1$ ) as a positive control. The result was further complimented by a real-time electricalimpedance-based detection method, and the migratory effect was slightly dose dependent (Figure 2c,d).

To measure the role of hBD3 on enterocyte migration in vivo, we examined the extent of intestinal restitution in a neonatal rat NEC model. The majority of 5-bromo$2^{\prime}$-deoxyuridine (BrdU)-positive cells in control animals had traveled along the villus and even reached the tips (Figure 2e). On the contrary, most of the staining cells in rats with NEC remained in the crypts (Figure 2f). Both the distance and extent of intestinal restitution were decreased in NEC rats compared with control animals. The impaired enterocyte migration in NEC was attenuated after hBD3 administration (Figure 2g,i,j). Taken together, these findings indicate that hBD3 treatment could promote enterocyte migration in vitro and in vivo.

\section{hBD3 Does Not Induce IEC Proliferation}

In response to injury, intestinal barrier is re-established by epithelial restitution and proliferation $(3,14)$. We next sought to determine the effects of hBD3 on enterocyte proliferation. After a 24- or 48-h incubation, proliferation of enterocytes was not significantly altered by either hBD3 or CCL20 (Figure 3a). To confirm the results, BrdU incorporation assay and cell cycle analysis were performed. The number of enterocytes labeled with BrdU did not increase significantly after hBD3 or CCL20 treatment when compared with unstimulated controls (Figure 3b). Data in Figure 3c showed that hBD3 or CCL20 stimulation did not increase the percentage of cells in $S$ phase. However, $10 \%$ fetal bovine serum markedly induced enterocyte proliferation.
To define whether hBD3 treatment could induce enterocyte proliferation in vivo, the terminal ileum in each group was immunostained with antiproliferating cell nuclear antigen (PCNA) antibody. The extent of enterocyte proliferation was evidently reduced in animals with NEC (Figure $3 \mathbf{d}-\mathrm{g}$ ) and was not improved by hBD3 administration (Figure 3d,h). Together, these data indicate that $\mathrm{hBD} 3$ could not induce IEC proliferation in vitro and in vivo.

\section{hBD3 Stimulates Enterocyte Migration via Action on CCR6}

hBD3 is known to interact with CCR6 by direct binding (15). And CCR6, the cognate receptor for ligand CCL20, is expressed by human enterocytes $(10,11)$. First, we confirmed the CCR6 expression in Caco-2 and IEC-6 cells by western blot. And the epithelial CCR6 expression was not increased after hBD3 treatment (Figure 4a). Immunofluorescence staining verified CCR6 localization at the cell surface (Figure 4b). In addition, as shown in Figure 4c-g, epithelial cells from ileum and colon expressed CCR6 both in newborn and adult rats. However, a reduction of CCR6 expression in neonatal rat was observed when compared with adult rat.

To determine the role of CCR6 in hBD3-stimulated cell migration, neutralizing anti-CCR6 antibody and specific CCR6 small interfering RNA (siRNA) were used to block CCR6 activation. In preliminary experiments, pretreatment with at least $2.5 \mu \mathrm{g} / \mathrm{ml} \mathrm{hBD} 3$ for $30 \mathrm{~min}$ could significantly decrease the migratory effect of hBD3 (Figure $4 \mathrm{~h}$ ). As shown in Figure 4i, CCR6 neutralizing antibody, but not control IgG, significantly inhibited hBD3- or CCL20-mediated enterocyte migration. We confirmed that neither CCR6 neutralizing antibody nor control IgG induced cell migration by itself. Moreover, pretreatment with CCR6 neutralizing antibody or control IgG did not reverse the TGF $\beta 1$-induced migration.

Next, CCR6 siRNA was transfected in Caco-2 cells, which resulted in a striking reduction in CCR6 expression compared with control siRNA (Figure 4j). Knockdown of CCR6 prevented further increases in enterocyte migration after subsequent $\mathrm{hBD} 3$ treatment (Figure $4 \mathrm{k}$ ).

CCR6 is a G-protein-coupled receptor activated mainly via the $G \alpha_{i}$ subunit. Therefore, we next sought to clarify the 
a

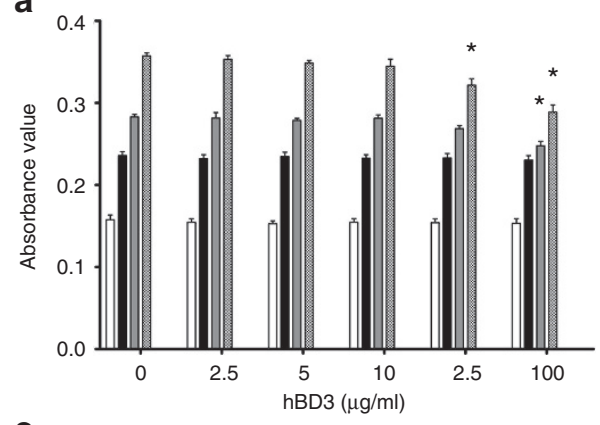

C

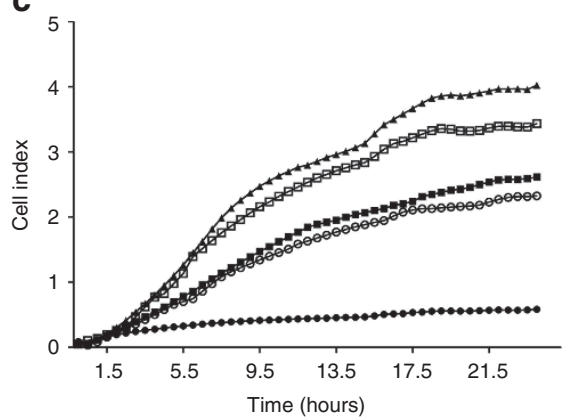

b

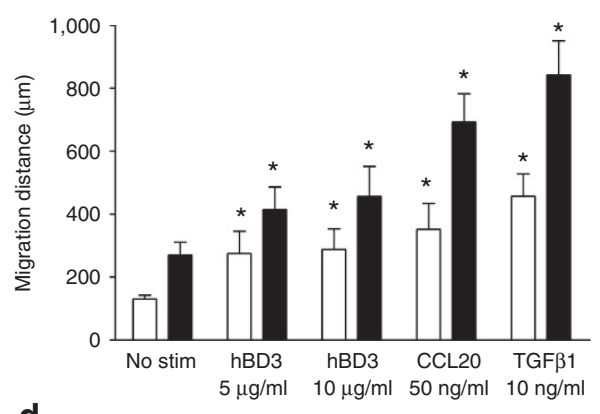

d

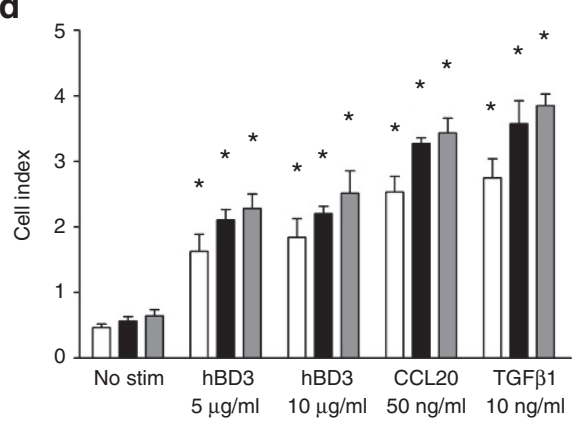

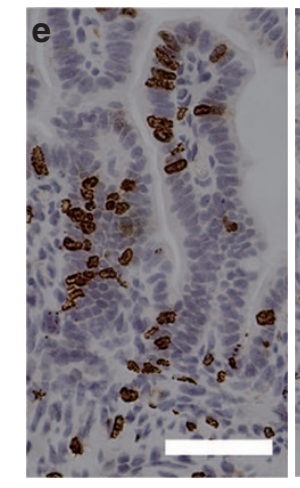

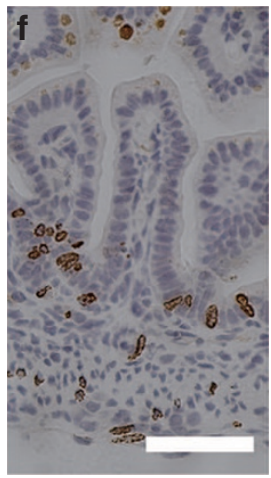

i

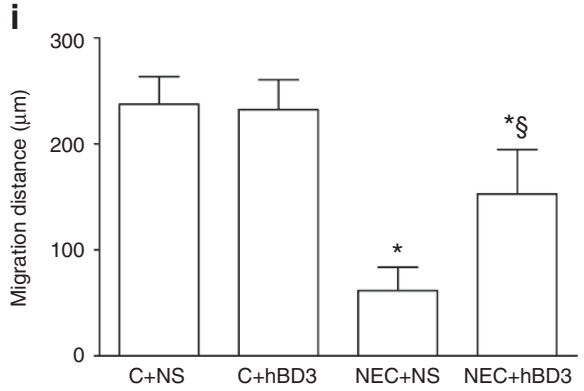

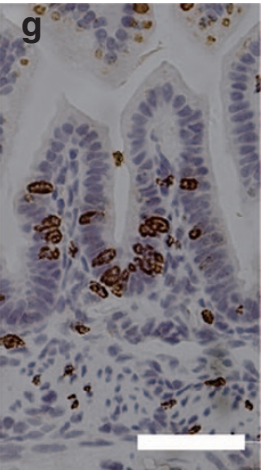
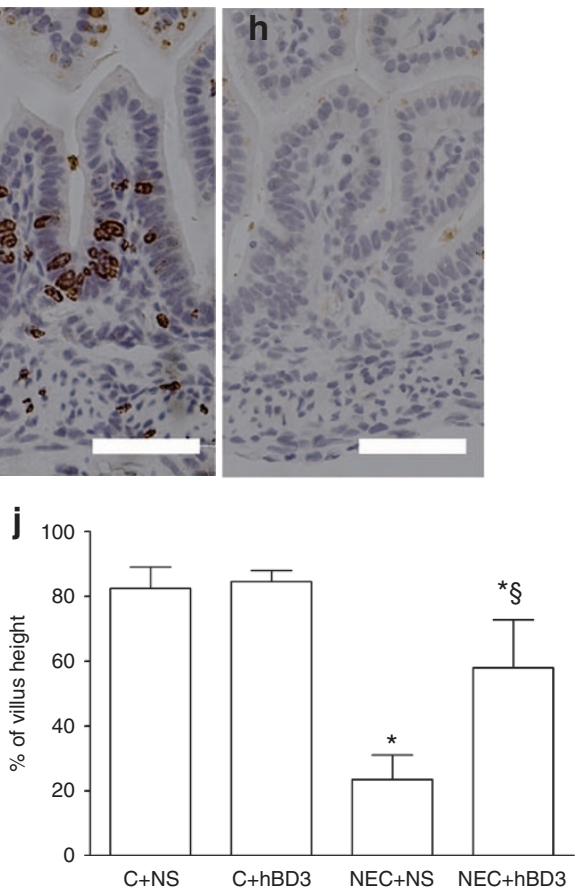

Figure 2. hBD3 stimulates enterocyte migration. (a) IEC- 6 cells were incubated with $0-100 \mu \mathrm{g} / \mathrm{ml} \mathrm{hBD} 3$ ( $12 \mathrm{~h}$, white bar; $24 \mathrm{~h}$, black bar; $48 \mathrm{~h}$, gray bar; $72 \mathrm{~h}$, hatched bar), and cell viability was determined by MTT assay, $n=5$. (b) Monolayer was wounded and left untreated (no stim), or treated with hBD3, CCL20, and TGF $\beta 1$ ( $12 \mathrm{~h}$, white bar; $24 \mathrm{~h}$, black bar). The traveled distance of 10 cells in fixed region of interest was measured, $n=10$. The real-time electrical-impedance data were collected during the experiment period ( $n=4$, in panel c, medium alone, filled circle; $5 \mu \mathrm{g} / \mathrm{ml} \mathrm{hBD} 3$, open circle; hBD3 $10 \mu \mathrm{g} / \mathrm{ml}$, filled square; CCL20, open square; TGF $\beta 1$, filled triangle. In d, $12 \mathrm{~h}$, white bar; $18 \mathrm{~h}$, black bar; $24 \mathrm{~h}$, gray bar). To assess enterocyte migration along the crypt-villus axis, (e,h) control and $(\mathbf{f}, \mathbf{g})$ necrotizing enterocolitis (NEC) rats were injected with BrdU $18 \mathrm{~h}$ before killing and immunostained with BrdU (magnification $\times 400)$. Bar $=$ $250 \mu \mathrm{m}$. (i) The migration distance and (j) the percentage of villus height achieved by the foremost labeled enterocyte were evaluated, $n=12-20$. ${ }^{*} P<0.05$ as compared between stimulated and nonstimulated cells, or between NEC+NS and NEC+hBD3 with $C+N S .{ }^{s} P<0.05$ between NEC+NS with NEC + hBD3.

involvement of $\mathrm{G \alpha}_{\mathrm{i}}$ signaling in cell migration. Pretreatment with pertussis toxin (PTX) partially decreased the hBD3-stimulated cell migration (Figure 4l). Together, these observations suggest that $\mathrm{hBD} 3$ stimulates enterocyte migration via the action on CCR6.
hBD3 Stimulates F-Actin Accumulation, MLC Phosphorylation, and ROCK and RhoA Activation

It has been reported that Rho-GTP, Rho-associated kinase (ROCK), phospho-myosin light chain 2 (MLC2), and F-actin polymerization were key regulators in cell migration 


\section{Articles $\mid$ shenget al.}

a

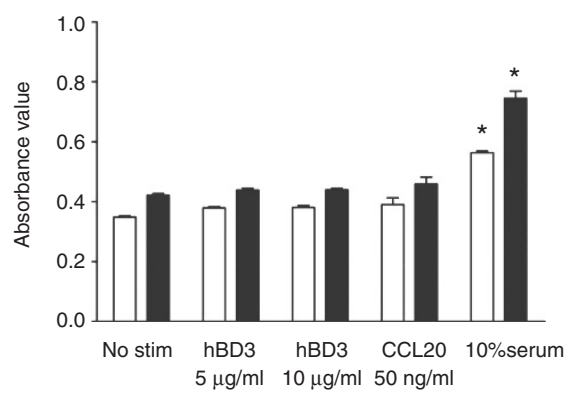

d

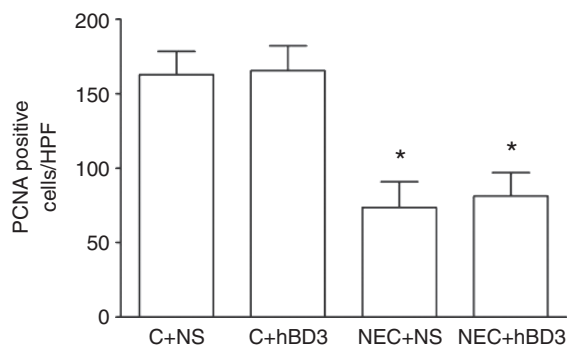

b
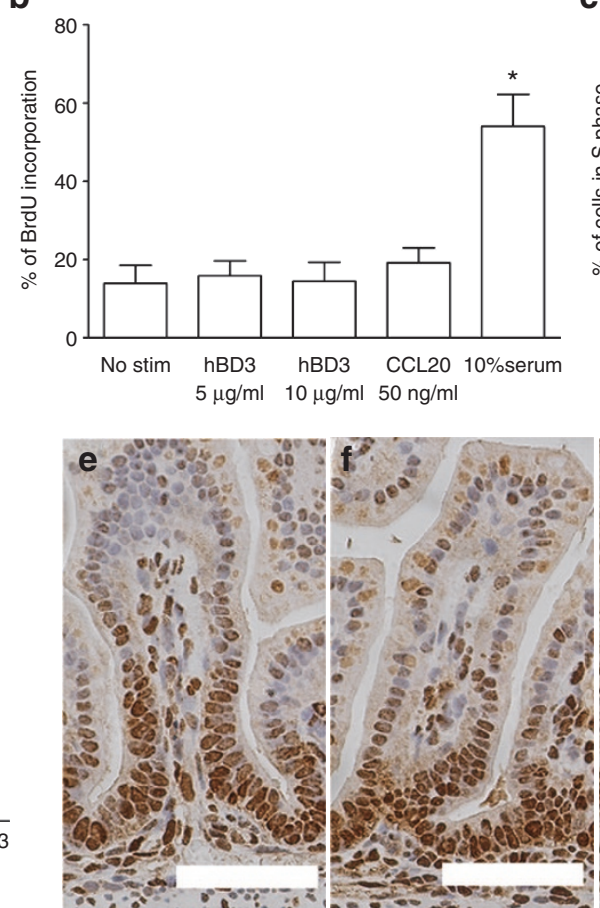

C
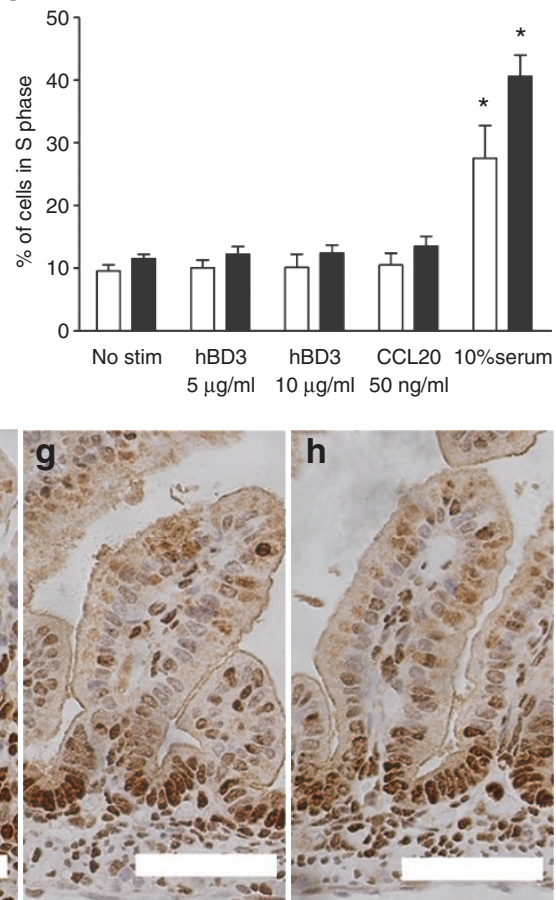

Figure 3. Effects of hBD3 on enterocyte proliferation. IEC- 6 cells were left untreated (no stim), or incubated with hBD3 (5, $10 \mu \mathrm{g} / \mathrm{ml}), \mathrm{CCL} 20$ ( $50 \mathrm{ng} / \mathrm{ml})$, or $10 \%$ serum for $24-48 \mathrm{~h}$. (a) CCK-8 analysis ( $24 \mathrm{~h}$, white bar; $48 \mathrm{~h}$, black bar), $n=5$. (b) BrdU incorporation assay. Data are expressed as the percentage of BrdU positive cells, $n=10$. (c) The percentage of cells in S phase was calculated by flow cytometry ( $24 \mathrm{~h}$, white bar; $48 \mathrm{~h}, \mathrm{black}$ bar), $n=5$. PCNA immunostaining was performed on the sections of terminal ileum from $(\mathbf{e}, \mathbf{f})$ control and $(\mathbf{g}, \mathbf{h})$ necrotizing enterocolitis (NEC) rats that were treated with normal saline (NS) or hBD3 (magnification $\times 400$ ). Bar $=250 \mu \mathrm{m}$. (d) Quantification of PCNA staining in crypts was assessed, $n=12-24 .{ }^{*} P<0.05$ as compared between stimulated and nonstimulated cells, or between NEC+NS and NEC+hBD3 with C+NS.

$(16,17)$. However, the effects of hBD3 on this pathway are still unknown. Thus, we first determined the accumulation of F-actin in Caco-2 cells after hBD3 or CCL20 incubation by fluorescein isothiocyanate-phalloidin staining and flow cytometry (Figure $5 \mathrm{a}-\mathrm{c}$ ). hBD3 treatment could increase about 35\% of F-actin accumulation compared with controls.

Phosphorylation of MLC2 plays a significant role in the regulation of the assembly of stress fibers (18). Figure $5 d$ showed that $\mathrm{hBD} 3$ treatment increased phosphorylation of MLC2 at serine 19 .

Then, we examined the effects of hBD3 on Rho activation. GTP-bound form of Rho increases actin dynamics through regulating the downstream effector ROCK. Of note, hBD3 treatment could increase the formation of activated Rho (Rho-GTP, Figure 5d,e).

ROCK, a direct effector molecule of RhoA, phosphorylates the myosin binding subunit of myosin phosphatase and inhibits the phosphatase activity (17). ROCK is also known to directly phosphorylate MLC. Therefore, we last investigated the participation of ROCK in hBD3-induced migration using the selective ROCK inhibitor Y27632. ROCK inhibition resulted in striking reduction of enterocyte migration (Figure 5f) and F-actin accumulation (Figure 5g). Taken together, we conclude that hBD3-stimulated enterocyte migration is mediated via a canonical Rho-ROCK signaling pathway and correspondingly increased F-actin accumulation.

\section{hBD3 Reduces the Incidence and Severity of NEC in Rat Model}

Because hBD3 was administered via gastric tube, antimicrobial activity of hBD3 was first assessed at $\mathrm{pH} 1.8, \mathrm{pH} 3.2, \mathrm{pH}$ 5.8, and $\mathrm{pH}$ 8.5. For both microorganisms, hBD3 activity was maintained throughout a broad $\mathrm{pH}$ range. The bactericidal effect of hBD3 was slightly inhibited at $\mathrm{pH} 8.5$ for $E$. coli, and at pH 5.8 for S. aureus (Figure 6a,b).

We next sought to determine the physiologic relevance of these findings in the intervention of NEC. Body weight of rats in group NEC+NS gradually decreased throughout the experiment, whereas neonatal rats in group NEC+hBD3 could maintain the body weight during the same period (Table 1). And differences in body weight between NEC+NS and NEC+hBD3 groups became statistically significant at day $4(P=0.015)$. Mother-fed pups showed steady increases in body weight. There were no differences in body weight gain between $\mathrm{C}+\mathrm{NS}$ and $\mathrm{C}+\mathrm{hBD} 3$ groups.

Macroscopic and microscopic examination of the gut showed clear evidence of intestinal injury similar to neonatal NEC (Figure 6e-i). The incidence, survival rate, and histological score in each group were shown in Table 2. Mother-fed rats did not develop NEC and showed no changes or abnormalities in the small intestinal structure. The incidence of NEC was reduced from $80 \%(16 / 20)$ in group 3 to $50 \%(12 / 24)$ in group $4(P=0.039)$. Mean NEC scores in these two groups were 2.50 and 1.67, respectively ( $P=0.01$, Figure $6 \mathrm{c})$. The survival rate $(96 \mathrm{~h})$ increased from $25 \%(5 / 20)$ in group 3 to $62.5 \%(15 / 24)$ in group $4(P<0.001$, Figure $6 \mathrm{~d})$. Administration of hBD3 
a

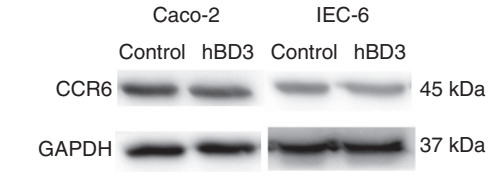

C

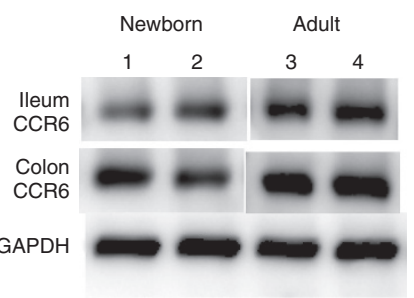

h

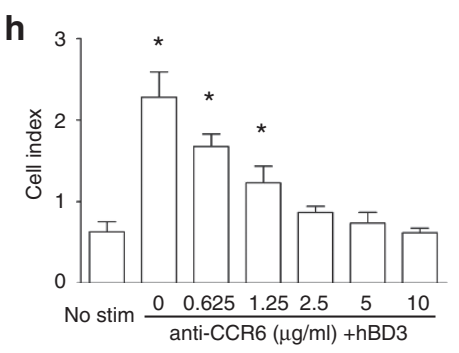

j
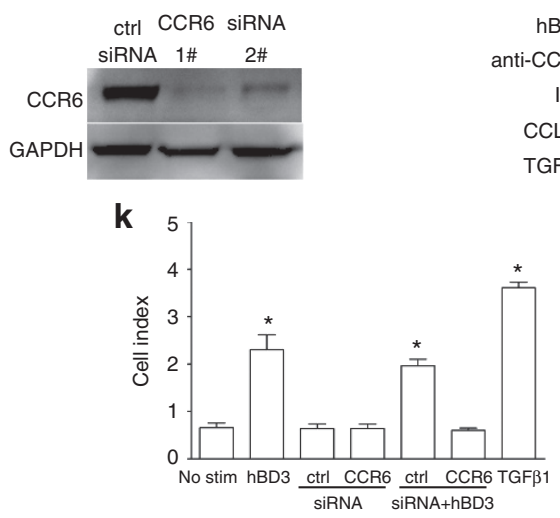

b

i
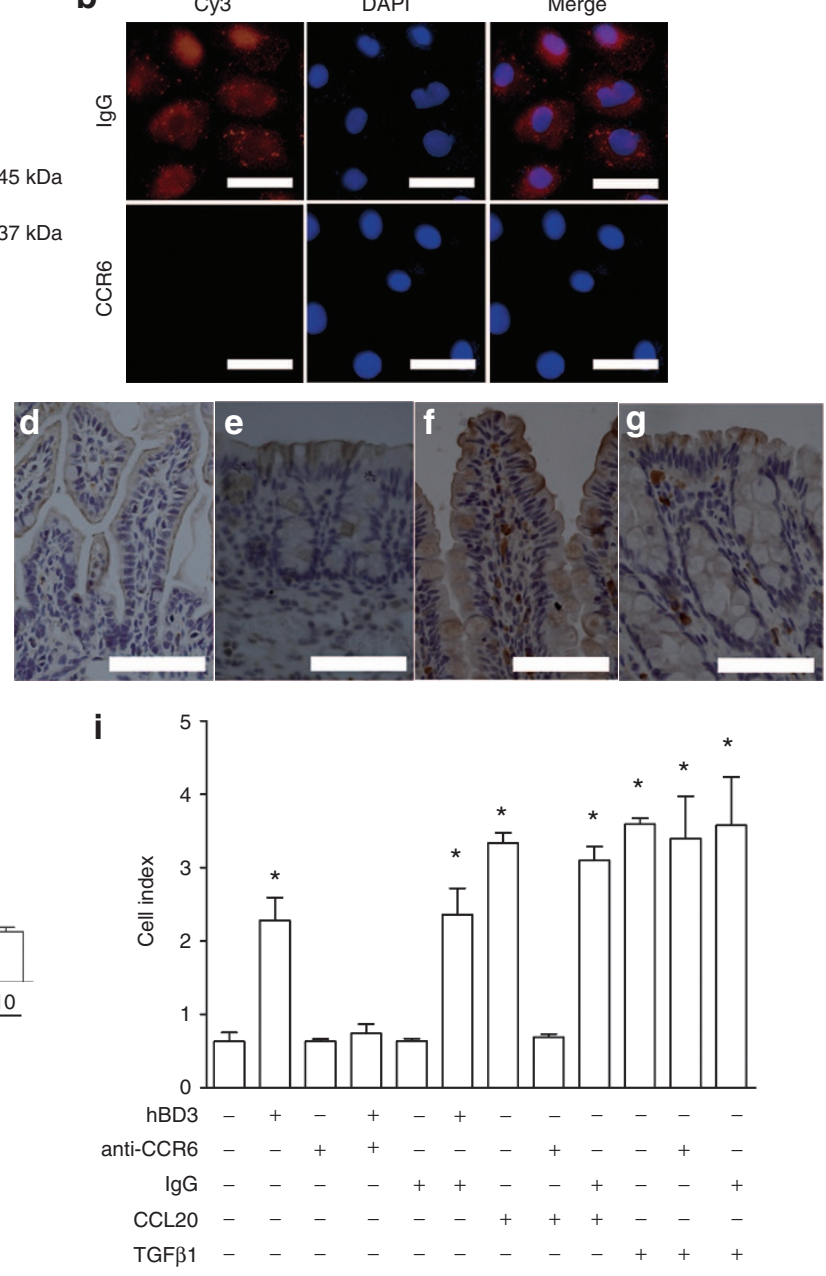

I

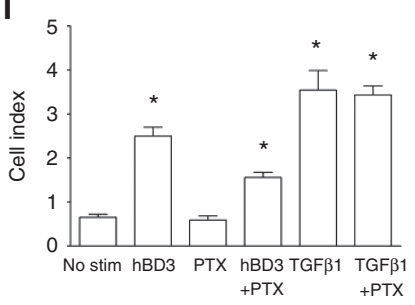

Figure 4. CCR6 mediates hBD3-induced intestinal epithelial cell migration. (a) Western blot analysis: CCR6 expression was not changed after incubation with $5 \mu \mathrm{g} / \mathrm{ml} \mathrm{hBD3}$ for $12 \mathrm{~h}$. (b) Caco-2 cells were immunostained with CCR6 or control lgG. CCR6 localization and nuclei were visualized by fluorescence microscopy (magnification $\times 400$ ). Bar $=10 \mu \mathrm{m}$. (c) SDS-PAGE demonstrated CCR6 expression in mucosal scrapings of ileum and colon obtained from two newborn pups (lanes 1 and 2) and two adult rats (lanes 3 and 4). Immunostaining of CCR6 in sections of either normal newborn (d) ileum and (e) colon, or healthy adult (f) ileum and (g) colon. Both ileal and colonic epithelium are stained positively for CCR6 (magnification $\times 400$ ). Bar $=250 \mu \mathrm{m}$. (h) Anti-CCR6 neutralizing antibody caused a dose-dependent inhibitory effect in the extent of enterocyte migration stimulated by hBD3. (i) Caco-2 cells were pretreated with $5 \mu \mathrm{g} / \mathrm{ml}$ neutralizing CCR6 antibody or $5 \mu \mathrm{g} / \mathrm{ml} \mathrm{lgG}$ control. Then medium alone, $5 \mu \mathrm{g} / \mathrm{ml} \mathrm{hBD3}, 50 \mathrm{ng} / \mathrm{ml} \mathrm{CCL20,} \mathrm{or} 10 \mathrm{ng} / \mathrm{ml} \mathrm{TGF} \beta 1 \mathrm{were}$ applied and cell migration was evaluated. (j) SDS-PAGE of CCR6 and GAPDH expression in Caco-2 cells transfected with CCR6 siRNA (1\#, 2\#) or control siRNA (ctrl siRNA). (k) Migration in Caco-2 cells treated with CCR6 siRNA (1\#) or ctrl siRNA. (I) Caco-2 cells were pretreated with $200 \mathrm{ng} / \mathrm{ml}$ PTX. Then, $5 \mu \mathrm{g} / \mathrm{ml} \mathrm{hBD3} \mathrm{or} 10 \mathrm{ng} / \mathrm{ml}$ TGF $\beta 1$ were applied and cell migration was evaluated. Values are mean $\pm \mathrm{SD}, n=4 .{ }^{*} P<0.05$ as compared between stimulated and nonstimulated cells.

also increased mean survival time of rat pups $(74.5 \pm 15.8$ and $86.7 \pm 13.8$ h, respectively).

\section{hBD3 Decreases Proinflammatory Mediators Expression and Preserves Mucosal Integrity}

Many studies have evaluated that the inflammatory cascade is central to NEC process $(1,19)$. Therefore, we measured cytokines expression in ileum and in serum. There were no differences of all the three cytokines expression between the two mother-fed groups. The ileum mRNA expression of tumor necrosis factor- $\alpha$ (TNF- $\alpha$ ), interleukin-6 (IL-6), and IL-10 were upregulated in the NEC+NS group compared with that in the C+NS group (4.77-, 13.74-, and 3.11-fold increase, respectively). hBD3 treatment decreased these 

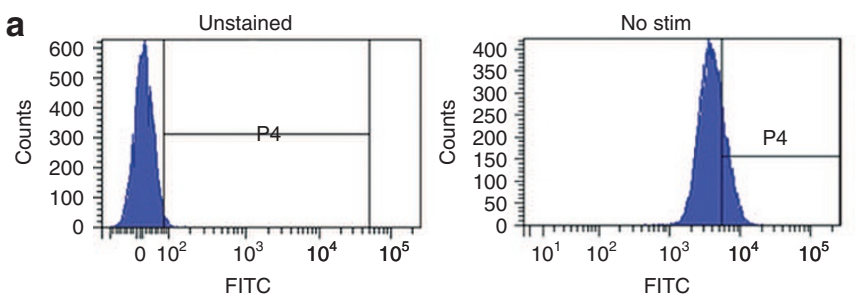

d
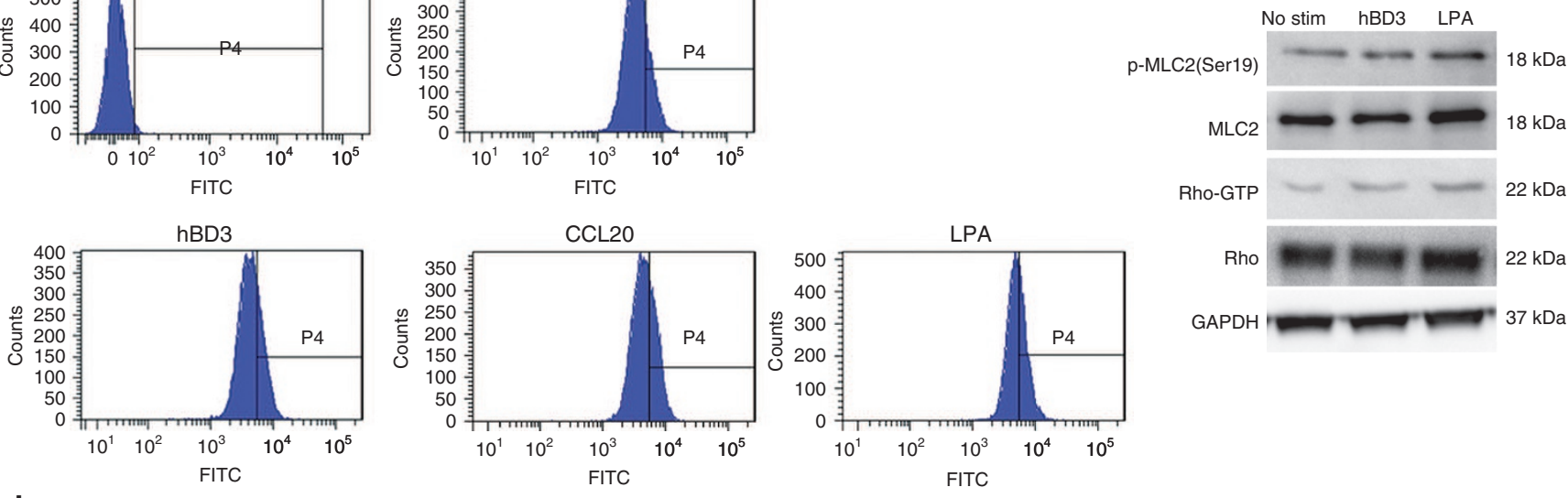

b

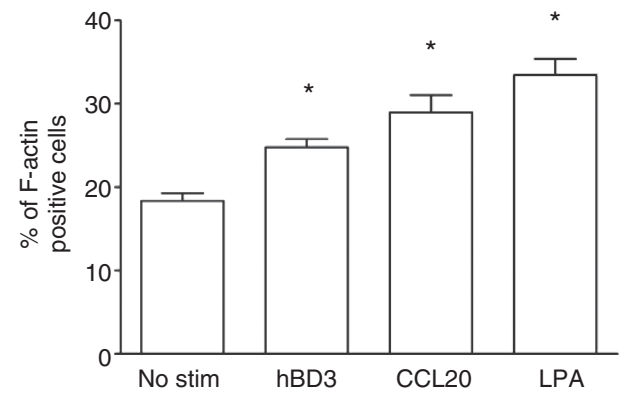

c
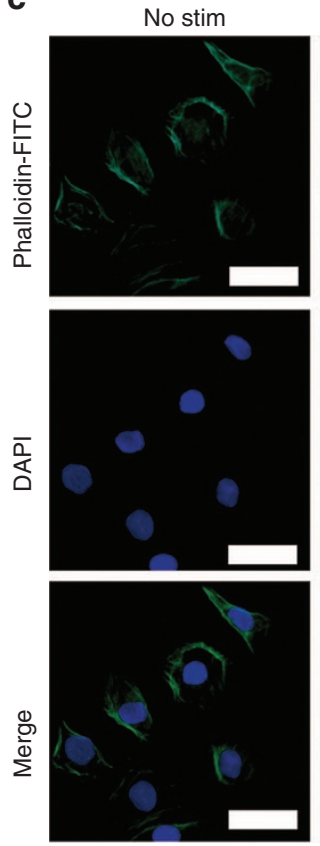

hBD
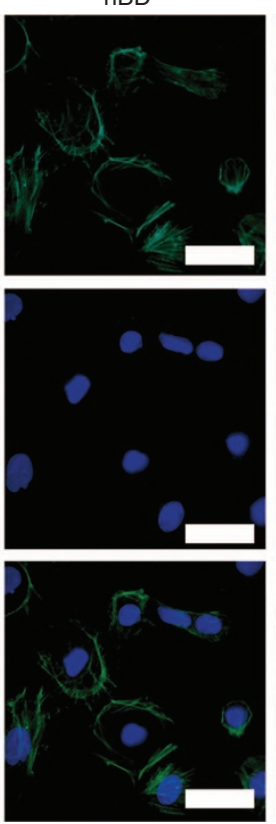

LPA
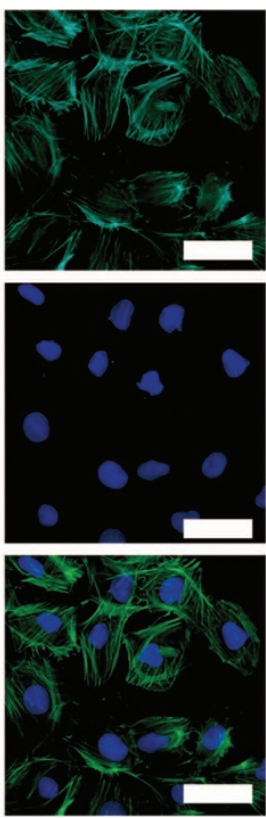

e

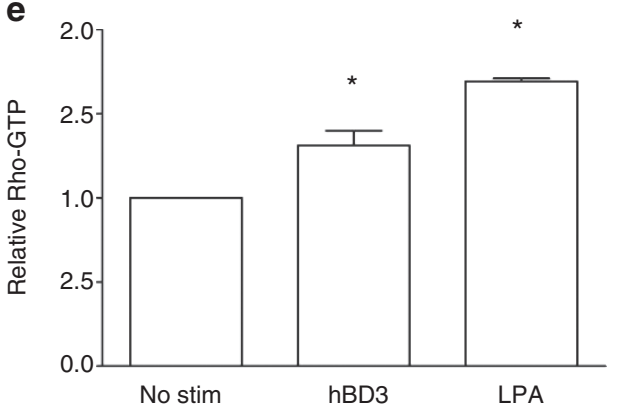

f
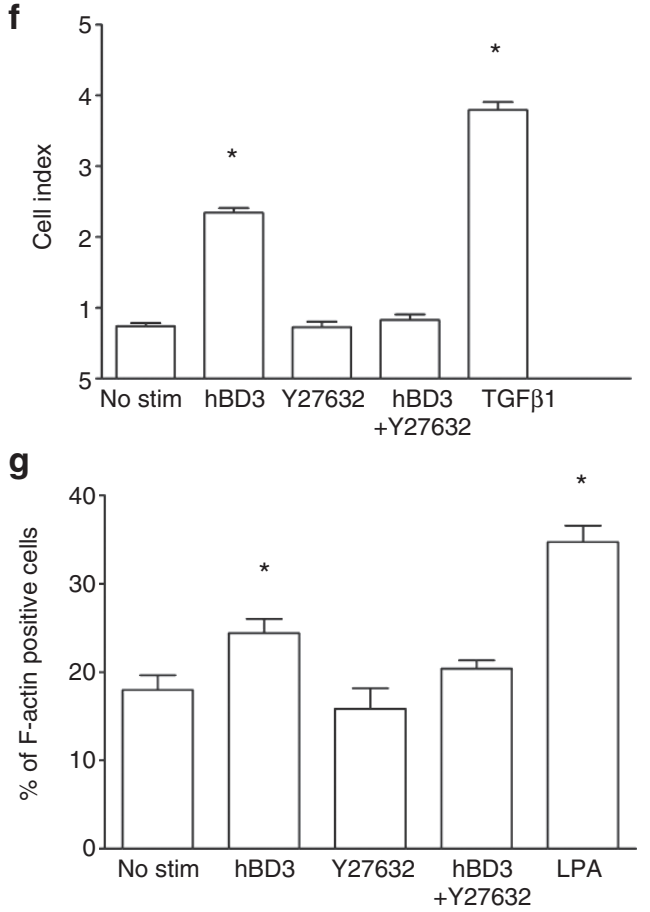

Figure 5. hBD3 regulates Rho activation and its downstream effectors. (a-c) Caco-2 cells were left untreated (No stim), or incubated with $5 \mu \mathrm{gg} / \mathrm{ml} \mathrm{hBD} 3$, $50 \mathrm{ng} / \mathrm{ml} \mathrm{CCL20}$, or $1 \mu \mathrm{g} / \mathrm{ml}$ L- $\alpha$-lysophosphatidic acid. F-actin was stained using phalloidin-fluorescein isothiocyanate (FITC) and analyzed by (a) flow cytometry (representative histogram) and (c) fluorescence microscopy (magnification $\times 400$ ), $n=5$. Bar $=10 \mu$ m. (d) MLC2 phosphorylation (Ser19) was increased after hBD3 treatment. Total MLC2 was assessed as a loading control. (d,e) Rho-GTP was induced by hBD3, and total Rho was used as a loading control. Caco-2 cells were pretreated with ROCK inhibitor Y27632 $(10 \mu \mathrm{mol} / \mathrm{l})$. (f) Cell migration and $(\mathbf{g})$ F-actin staining were evaluated respectively, $n=$ 4-5. ${ }^{*} P<0.05$ as compared between stimulated and nonstimulated cells.

inflammatory mediators mRNA expression in the ileum $(P<0.05$, Figure $7 \mathrm{a}-\mathrm{c})$. Next, the effect of hBD3 on the serum concentration of TNF- $\alpha$ was measured by enzyme-linked immunosorbent assay (ELISA). The TNF- $\alpha$ level was significantly higher in NEC rats compared with controls $(P<$ 0.05 , Table 3, Figure $7 d$ ). And, hBD3 administration could 

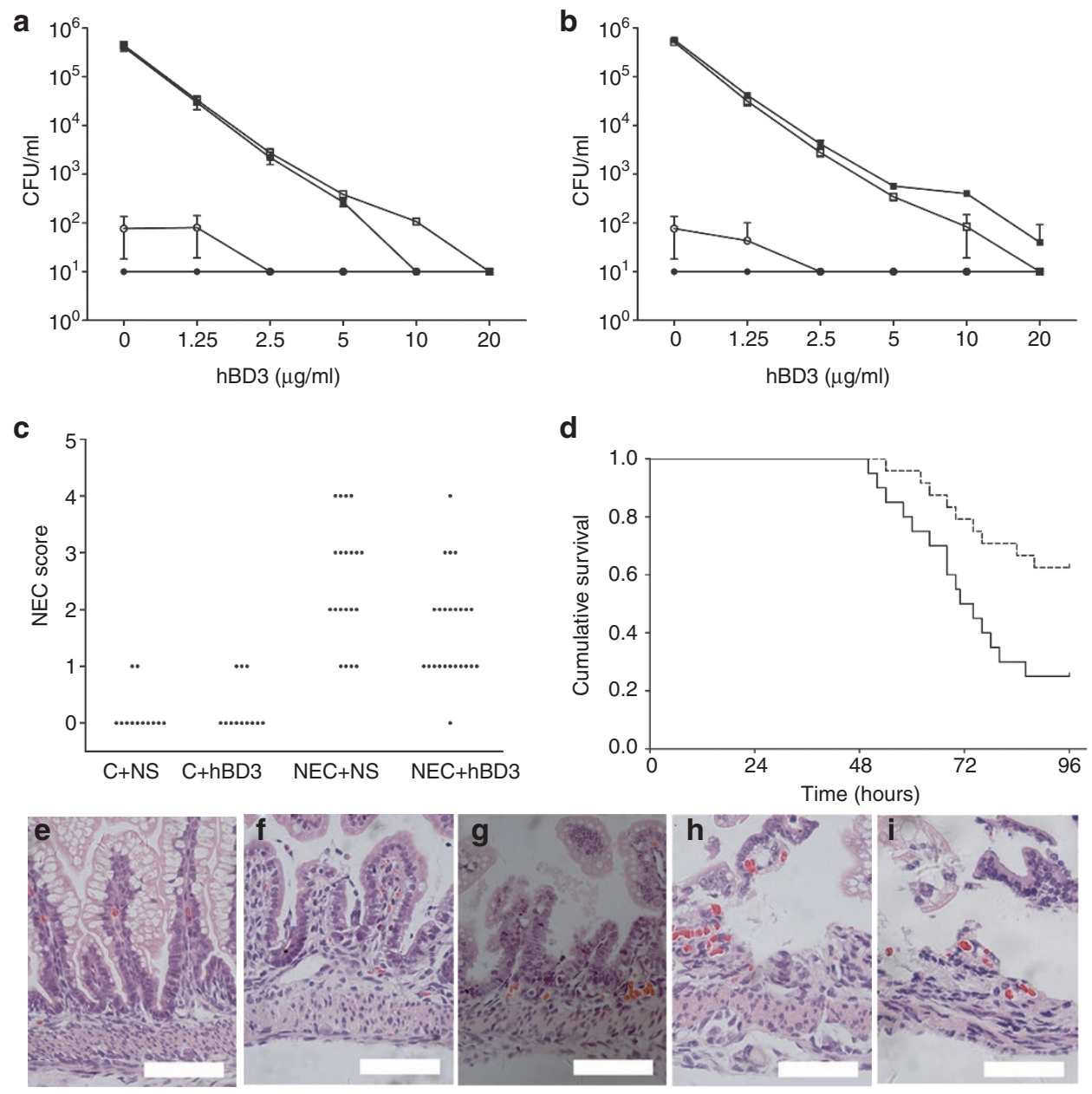

Figure 6. Effects of hBD3 on neonatal rat necrotizing enterocolitis (NEC) model. Bactericidal activities of hBD3 against clinical isolates (a) Escherichia coli and (b) Staphylococcus aureus after $2 \mathrm{~h}$ of incubation in $10 \mathrm{mmol} / \mathrm{I}$ sodium phosphate buffer ( $\mathrm{pH}$ 1.8, filled circle; $\mathrm{pH} 3.2$, open circle; $\mathrm{pH} 5.8$, filled square; $\mathrm{pH} 8.5$, open square), $n=3$. (c) Summary of histological NEC score in each group. (d) Survival time was analyzed by Kaplan-Meier survival analysis (NEC+hBD3, dashed; NEC+NS, solid). Histological scores of distant ileum from neonatal rats (magnification $\times 400)$. (e) Grade 0, normal ileum; (f) grade 1, mild injury in villous tips; (g) grade 2, partial loss of villi; (h) grade 3, severe damage to submucosa; (i) grade 4, full necrosis. Bar $=250 \mu \mathrm{m}$.

Table 1. Body weight ( $g$ ) of neonatal rats during the experiment

\begin{tabular}{lcccc}
\hline Group & D1 & D2 & D3 & D4 \\
\hline C+NS & $5.09 \pm 0.14$ & $6.52 \pm 0.27$ & $7.73 \pm 0.38$ & $8.80 \pm 0.28$ \\
C+hBD3 & $5.21 \pm 0.29$ & $6.33 \pm 0.32$ & $7.52 \pm 0.36$ & $8.72 \pm 0.55$ \\
NEC+NS & $5.39 \pm 0.30$ & $5.26 \pm 0.27^{\mathrm{a}}$ & $5.08 \pm 0.29^{\mathrm{a}}$ & $4.91 \pm 0.26^{\mathrm{a}}$ \\
NEC+hBD3 & $5.35 \pm 0.54$ & $5.27 \pm 0.66^{\mathrm{a}}$ & $5.22 \pm 0.65^{\mathrm{a}}$ & $5.36 \pm 0.55^{\mathrm{a}, \mathrm{b}}$ \\
\hline
\end{tabular}

Data are presented as mean \pm SD.

NEC, necrotizing enterocolitis.

aStatistical significance with $P<0.05$ (NEC+NS and NEC+hBD3 vs. C+NS or C+hBD3).

${ }^{b}$ Statistical significance with $P<0.05$ (NEC+NS vs. NEC+ hBD3).

evidently reduce the serum level of TNF- $\alpha$, although not to normal baseline.

We next investigated the effect of hBD3 on the inflammatory cytokines expression in cultured enterocytes. IEC-6 cells were incubated with various concentrations of hBD3 for $1-24 \mathrm{~h}$, and $\mathrm{hBD} 3$ treatment did not induce the mRNA expression of TNF- $\alpha$ (Figure 7e). Moreover, after incubation with hBD3 for $48 \mathrm{~h}$, the production of TNF- $\alpha$ in supernatants did not increase evidently (Figure 7f). However, we
Table 2. Effects of hBD3 on neonatal rats

\begin{tabular}{lccc}
\hline Group & $\begin{array}{c}\text { Incidence } \\
\text { rate of NEC }\end{array}$ & Survival rate & $\begin{array}{c}\text { NEC score } \\
(\text { mean } \pm \text { SD) }\end{array}$ \\
\hline C+NS & $0 \%(0 / 12)$ & $100 \%(12 / 12)$ & $0.17 \pm 0.39$ \\
C+hBD3 & $0 \%(0 / 12)$ & $100 \%(12 / 12)$ & $0.25 \pm 0.45$ \\
NEC+NS & $80 \%(16 / 20)$ & $25 \%(5 / 20)$ & $2.50 \pm 1.05$ \\
NEC+hBD3 & $50 \%(12 / 24)^{\mathrm{a}}$ & $62.5 \%(15 / 24)^{\mathrm{a}}$ & $1.67 \pm 0.92^{\mathrm{a}}$ \\
\hline
\end{tabular}

NEC, necrotizing enterocolitis.

aStatistical significance with $P<0.05$ between NEC+NS and NEC + hBD3 groups.

have observed a slight increase of TNF- $\alpha$ at a higher concentration $(25 \mu \mathrm{g} / \mathrm{ml})$.

To test the effect of hBD3 on the intestinal mucosal integrity, we detected the serum level of diamine oxidase (DAO), an indicator of intestinal injury (20). Decreased levels of DAO activity were detected in the NEC+NS group (Table 3, Figure $7 \mathrm{~g}$ ). And hBD3 treatment increased the concentration of DAO in the serum $(P<0.05)$. Furthermore, histological expression of tight junction protein zonula occludens-1 (ZO-1) was evaluated. ZO-1 staining was lost in rat pups 
a

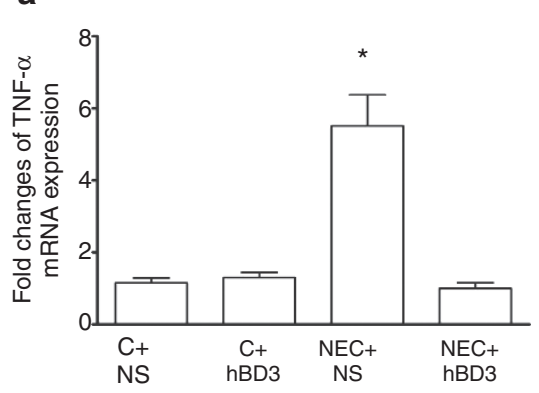

b

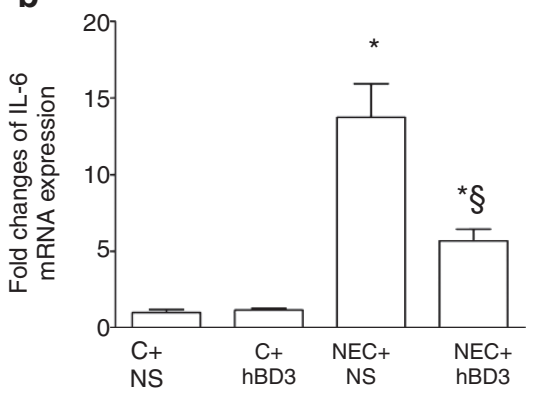

C

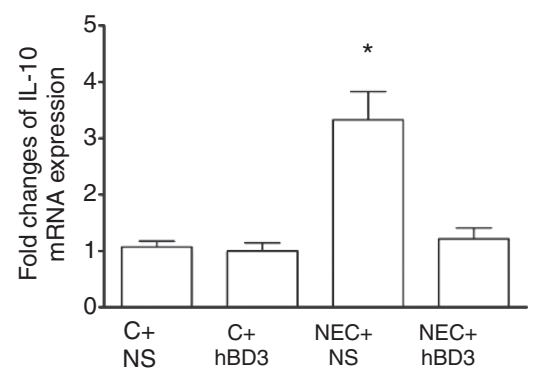

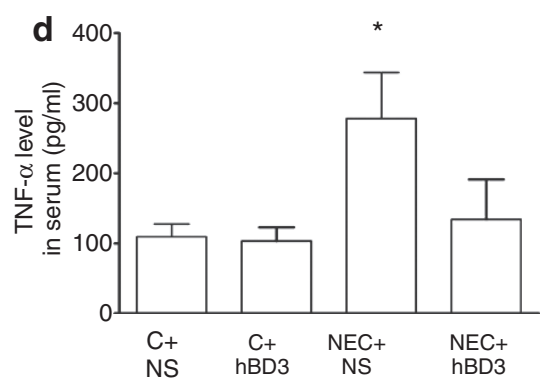
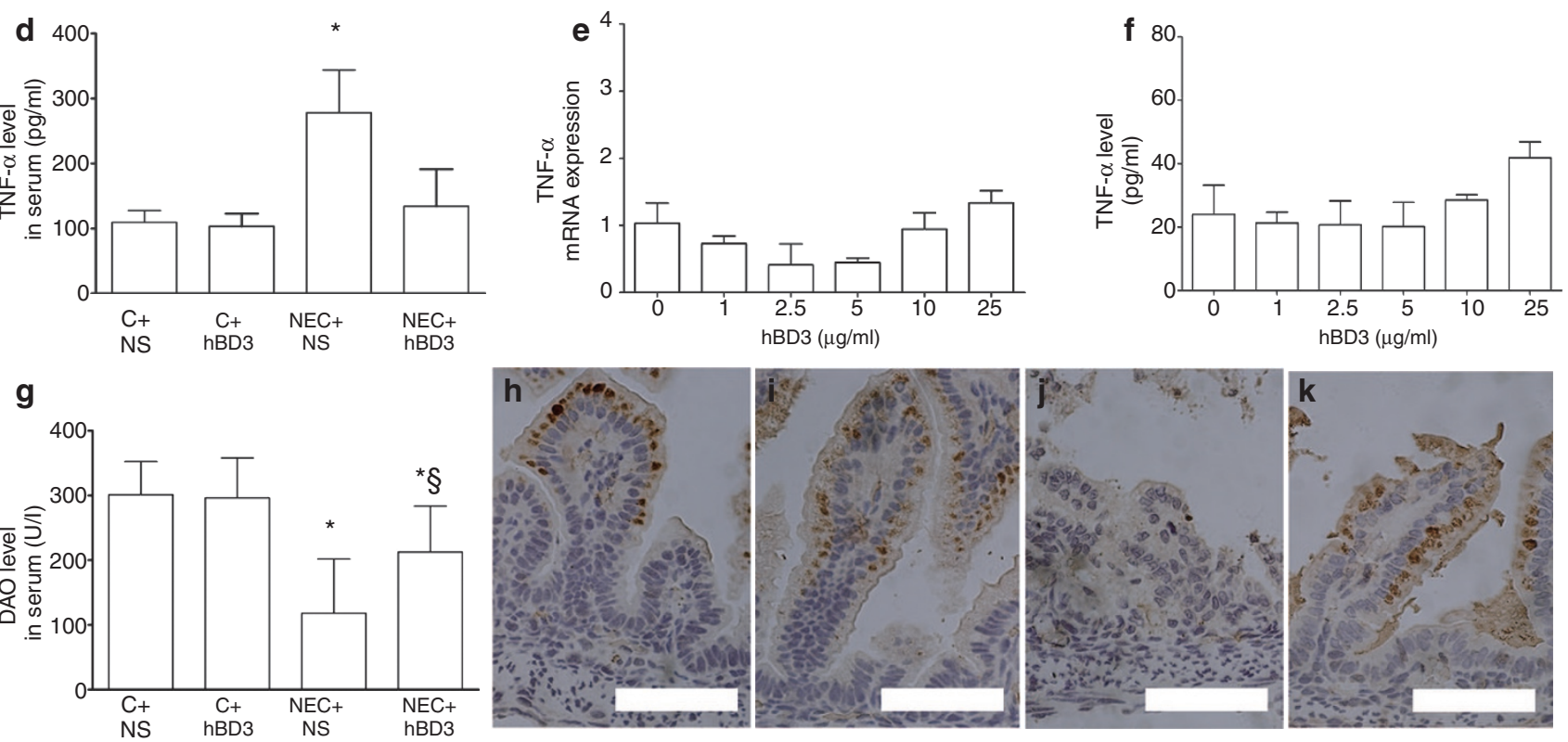

Figure 7. Effects of hBD3 on inflammatory cytokines expression and mucosal integrity. Relative mRNA expression of (a) tumor necrosis factor- $\alpha$ (TNF- $\alpha$ ), (b) interleukin (IL)-6, and (c) IL-10 in the ileum of rats among four groups was calculated. (d) TNF- $\alpha$ level in the serum was assessed using ELISA. (e) Realtime PCR and (f) ELISA showed the expression of TNF- $\alpha$ in IEC-6 or in the supernatants, respectively. (g) Diamine oxidase (DAO) level in the serum was evaluated. ZO-1 was immunostained on the sections of terminal ileum from $(\mathbf{h}, \mathbf{i})$ control and $(\mathbf{j}, \mathbf{k})$ necrotizing enterocolitis (NEC) rats that were treated with normal saline (NS) or hBD3 (magnification $\times 400)$. Bar $=250 \mu \mathrm{m} .(\mathbf{a}-\mathbf{d}, \mathbf{g}) n=12-24,(\mathbf{e}, \mathbf{f}) n=3$. ${ }^{*} P<0.05$ as compared between NEC+NS and NEC+ hBD3 with $\mathrm{C}+\mathrm{NS} .{ }^{5} \mathrm{P}<0.05$ between NEC+NS with NEC+ hBD3.

Table 3. TNF- $\alpha$ and DAO levels in the serum

\begin{tabular}{lcccc}
\hline Group & C + NS & C + hBD3 & NEC+NS & NEC+hBD3 \\
\hline TNF- $\alpha(\mathrm{pg} / \mathrm{ml})$ & $109.37 \pm 18.24$ & $103.41 \pm 19.56$ & $278.21 \pm 65.59^{\mathrm{a}}$ & $134.27 \pm 56.99^{\mathrm{b}}$ \\
DAO $(\mathrm{U} / \mathrm{l})$ & $301.20 \pm 51.37$ & $296.51 \pm 61.66$ & $117.81 \pm 83.98^{\mathrm{a}}$ & $212.79 \pm 70.78^{\mathrm{a}, \mathrm{b}}$ \\
\hline
\end{tabular}

Data are presented as mean \pm SD.

DAO, diamine oxidase; NEC, necrotizing enterocolitis; TNF- $\alpha$, tumor necrosis factor- $\alpha$.

a statistical significance with $P<0.05$ (NEC+NS and NEC+hBD3 vs. C+NS or C+hBD3). bStatistical significance with $P<0.05$ (NEC+NS vs. NEC+ hBD3).

exposed to NEC stress when compared with mother-fed pups (Figure $7 \mathbf{h}-\mathbf{j}$ ). This alteration in $\mathrm{ZO}-1$ was prevented by hBD3 administration (Figure 7k).

Taken together, these data demonstrate that hBD3 decreases the expression of proinflammatory mediators both in ileum and in serum and preserves the intestinal mucosal integrity.

\section{DISCUSSION}

The genomic and three-dimensional structural studies provide a convincing evidence for the high degree of conservation among defensins, chemokines, and chemokine receptors.
Comparing of the solution structures of $\mathrm{hBD} 3$ and rodent CCL20, the presence of $\mathrm{NH}_{2}$-terminal Asp-Cys-Cys-Leu (DCCL) motif is considered to be responsible for their capacity to bind with the same receptor CCR6 $(12,21,22)$. Our data showed CCR6 is widely expressed by epithelial cells in the ileum and colon of neonatal and adult rats. Blockage of CCR6 by neutralizing antibody and specific siRNA verified that $\mathrm{hBD} 3$-induced cell migration was mediated by CCR6. In addition, inhibition of the $\mathrm{G}_{\mathrm{i}}$ subunit by PTX resulted in a significantly reduced migratory response without returning to the baseline. The incomplete inhibition suggested that other 
signaling molecules may be involved such as phosphoinositide 3-kinase signaling pathway.

The active form of Rho family (GTP-bound) regulates actin dynamics and coordinates cell motility. In this study, we showed that $\mathrm{hBD} 3$ treatment could stimulate Rho activation and in turn activate its downstream signaling pathway. However, RhoA triggers many target signaling molecules (17). The effects of hBD3 on other RhoA targets such as mammalian diaphanous formins (mDial) need further investigation. Furthermore, hBD3 activated different types of cells through alternative pathways, i.e., the $\mathrm{G}$ protein and phospholipase $\mathrm{C}$ signaling pathway in human keratinocytes (23) and the canonical (p65/RelA) NF- $\kappa B$ signaling pathway in human monocytes (24).

Previous studies confirmed that the majority of healthy preterm newborns secrete gastric acid in quantity sufficient to maintain the $\mathrm{pH}$ value in a range of 3.2-6.5. These changes in $\mathrm{pH}$ could affect the bactericidal activity of hBD3 by modifying the peptide or its target. However, our results demonstrated that hBD3 activity was maintained throughout a broad $\mathrm{pH}$ range. On the basis of extensive experimental and human investigations, it is clear that multiple risk factors of NEC stimulate the proinflammatory response that ultimately leads to intestinal injury. In addition, inflammatory mediators are known to induce barrier dysfunction $(3,19)$. From our study, the expression of inflammatory cytokines, including TNF- $\alpha$ and IL-6, was upregulated in pups with NEC. And the intestinal mucosal integrity was also impaired in NEC rats. Enteral administration of hBD3 decreased the overproduction of proinflammatory cytokines and preserved mucosal integrity, but did not increase anti-inflammatory cytokine IL-10 production. One possible explanation is that the protective effect of hBD3 is not mediated by IL- 10 .

The molecular mechanisms underlying $\mathrm{hBD} 3$ protection are complex. First, compared with hBD1 and hBD2, hBD3 contains significantly more positively charged residues and possesses a stronger bactericidal activity. The bactericidal activity of defensins in vitro does not necessarily imply its ability in vivo. However, findings in knockout mice (matrilysin deficient) suggested that direct pathogen clearance was at least one mechanism of defensin function (25). Second, antimicrobial peptides, including hBD3, have been shown to demonstrate a biphasic effect, being proinflammatory at higher concentrations, but anti-inflammatory at lower levels $(23,26,27)$. In contrast, our data showed hBD3 did not increase the expression of TNF- $\alpha$ in enterocytes. However, TNF- $\alpha$ production is slightly increased after incubation with a higher concentration of hBD3. Although the exact concentration of hBD3 in intestinal mucosa of newborns is still unknown, studies confirmed that $\mathrm{hBD} 3$ peptide was expressed in healthy lower gastrointestinal tract and the expression was selectively increased during inflammation and inflammatory bowel disease $(28,29)$. Thus, anti-inflammatory effect of hBD3 may also contribute to its beneficial function. Third, in this study, we introduced a new role of hBD3 in the prevention of NEC via regulation of intestinal restitution. Activation of Rho-ROCK signaling pathway leads to efficient enterocyte migration and intestinal barrier repair in NEC model. Fourth, there is little doubt that intestinal microbes are critically involved in the pathogenesis of NEC. Recent studies suggested defensin also serves to help shape the composition of the colonizing microbiota (30). It is possible that changes in the microbiota in response to hBD3 administration might be attributed in part to the protective effect. Obviously, there are other important factors within enterocyte itself or in the microenvironment participated in the pathogenesis of NEC. And the effects of hBD3 on these targets and its clinical relevance need further studies.

In summary, the data from our study, for the first time, indicated that hBD3 had protective effects on neonatal rats with NEC via reducing inflammatory mediators, preserving mucosal integrity, and promoting intestinal restitution. Our findings provide evidence that hBD3 functions as a key host defense peptide not only to its bactericidal and chemotactic activity, but also to its induction of wound healing in the gut.

\section{METHODS}

\section{Cell Cultures, Reagents, and Antibodies}

The Caco-2 (passages 22-28) and IEC-6 (passages 20-28) cell lines were obtained from American Type Culture Collection. Caco-2 was cultured in minimum essential medium supplemented with $10 \%$ heat-inactivated fetal bovine serum. IEC-6 was grown in Dulbecco's modified Eagle's medium supplemented with $10 \%$ fetal bovine serum. Recombinant hBD3 (E. coli derived, Prospec, Ness-Ziona, Israel); Recombinant human TGF $\beta 1$ and CCL20 (Peprotech, Rocky Hill, NJ); PTX, BrdU, fluorescein isothiocyanate-phalloidin, Y27632, and L- $\alpha$-lysophosphatidic acid (Sigma, St Louis, MO); Neutralizing antiCCR6 antibody and IgG control (R\&D Systems, Minneapolis, MN); BrdU, PCNA, ZO-1, and CKR-6 primary antibodies (Santa Cruz Biotechnology, Dallas, TX); GAPDH, MLC2, phospho-MLC2, and Rho primary antibodies (Cell Signaling Technology, Beverly, MA); CCR6 siRNA (GenePharma, Shanghai, China).

\section{Antimicrobial Assay}

The antimicrobial activity of hBD3 against clinical isolates E. coli and $S$. aureus was determined using a liquid microdilution assay. Test organisms were provided by Professor Hong Zhang (Children's Hospital of Shanghai). Exponentially growing bacteria were adjusted to a density of $10^{7} \mathrm{CFU} / \mathrm{ml}$. Ten microliters of each bacterial suspension was exposed to hBD3 $(0-20 \mu \mathrm{g} / \mathrm{ml})$ in $100 \mu \mathrm{l}$ sodium phosphate buffer ( $\mathrm{pH}$ 7.4) and incubated at $37^{\circ} \mathrm{C}$ for $2 \mathrm{~h}$. To investigate the effect of acid on hBD3 activity, sodium phosphate buffer was prepared at $\mathrm{pH} 1.8, \mathrm{pH} 3.2, \mathrm{pH} 5.8$, and $\mathrm{pH}$ 8.5. After the incubation period, serial dilutions of the assay culture were prepared and plated in triplicate onto Luria-Bertani broth (Oxoid, Hampshire, UK) plates. The number of colonies was counted the next morning.

\section{Cell Proliferation Assays}

Enterocyte proliferation in vitro was measured using Cell Counting Kit-8 (CCK-8, Beyotime, Shanghai, China), BrdU incorporation method, and cell cycle analysis $(2,23)$. Ten percentage of fetal bovine serum was used as a positive control. The methodology for quantification of enterocyte proliferation in vivo has been described by Sodhi et al. and Feng and Besner (2,31). PCNA-positive cells in the crypts were counted from five high power fields for each segment of intestine.

\section{Cell Migration Assays}

IEC-6 and Caco-2 cells were grown and a wound was created. Wounded monolayers were then cultured in defined concentrations of hBD3 or CCL20 for $24 \mathrm{~h}$. TGF $\beta 1$ was assessed as a positive control. The migration was monitored by measuring the mean traveled distance of 10 cells in fixed region of interest during the experiment. 
Table 4. Sequences of oligonucleotide primers

\begin{tabular}{lll}
\hline Target gene & \multicolumn{1}{c}{ Primer sequences (5' to 3') } & Product length \\
\hline $\begin{array}{l}\text { GAPDH } \\
\text { (human) }\end{array}$ & (F) GCGAGATCCCGCTAACATCA & $283 \mathrm{bp}$ \\
CCR6 & (R) CCCTTCCACGATGCCAAAGT & \\
(human) & (F) AGGGCCCACGTGTATATGCT & $173 \mathrm{bp}$ \\
$\beta$-actin (rat) & (R) GAGTGTATGGTTCAGCCCCT & \\
& (F) GCGTCCACCCGCGAGTACAA & $145 \mathrm{bp}$ \\
TNF- $\alpha$ (rat) & (R) CGACGACGAGCGCAGCGATA & \\
& (F) TGGGTCCAACTCCGGGCTCA & $117 \mathrm{bp}$ \\
IL-6 (rat) & (R) TGGAATCCTTGCCGGTGGCG \\
& (F) GTCTCGAGCCCACCAGGAACG & $132 \mathrm{bp}$ \\
IL-10 (rat) & (R) AGGGAAGGCAGTGGCTGTCAAC \\
& (F) GCAAGGCAGTGGAGCAGGTGA & $156 \mathrm{bp}$ \\
& (R) TGCAGTCCAGTAGATGCCGGGT & \\
\hline
\end{tabular}

$\mathrm{L}$, interleukin; TNF- $\alpha$, tumor necrosis factor- $\alpha$.

A second migration assay was completed on CIM-16 plates with the xCELLigence Real-time Cell Analyzer (ACEA Biosciences, San Diego, CA). The detailed procedures have been previously described by Rahim et al. and van Gils et al. $(32,33)$. In experiments that involved the combination of hBD3, CCL20, or TGF $\beta 1$ with another treatment, cells were pretreated with neutralizing CCR6 antibody $(0-10 \mu \mathrm{g} / \mathrm{ml}$, $30 \mathrm{~min})$, IgG control (5 $\mu \mathrm{g} / \mathrm{ml}, 30 \mathrm{~min})$, PTX (200 ng/ml, $1 \mathrm{~h})$, and Y27632 $(10 \mu \mathrm{mol} / \mathrm{l}, 1 \mathrm{~h})$, respectively.

To measure enterocyte migration in vivo, we followed the procedures described by Houle et al. and others $(31,34,35)$. Animals were injected with BrdU $(50 \mathrm{mg} / \mathrm{kg})$ intraperitoneally $18 \mathrm{~h}$ before sacrifice. Enterocyte migration was expressed in two ways: (i) by measuring the distance from the bottom of the crypt to the foremost labeled enterocyte and (ii) by expressing the migration distance as a percentage of total villus height (foremost labeled enterocyte/total villus height $\times 100$ ).

\section{RNA Interference}

Enterocytes were transfected with $80 \mathrm{nmol} / \mathrm{l}$ CCR6 siRNA, or control siRNA using Lipofectamine 2000 (Life, Grand Island, NY) as a carrier. The efficacy of knockdown was assessed by real-time PCR and western blot. Twenty-four hours after transfection, cells were further stimulated with other reagents.

\section{Determination of F-Actin Content and RhoA Activation}

To analyze cellular F-actin level, subconfluent enterocytes were serum-starved overnight before hBD3 or CCL20 treatment. Cells were fixed in $3.7 \%$ paraformaldehyde, permeabilized with $0.1 \%$ TRITON X-100, and then stained with $50 \mu \mathrm{g} / \mathrm{ml}$ fluorescein isothiocyanate-phalloidin. Images were acquired by fluorescence microscope. F-actin formation was further measured by flow cytometry. Rho activation levels were detected using the Active Rho Detection Kit (Cell Signaling Technology) according to the manufacturer's protocol. L- $\alpha$-Lysophosphatidic acid $(1 \mu \mathrm{g} / \mathrm{ml})$ or TGF $\beta 1(10 \mathrm{ng} / \mathrm{ml})$ were used as positive controls.

\section{Experimental Design, Animal Model, and NEC Evaluation}

All experimental protocols were approved by the Animal Care Committee of the Children's Hospital of Shanghai. Newborn male Sprague-Dawley rats were collected by cesarean section on day 21.5 of gestation. We used the rat NEC model described by Caplan et al. and further developed in our laboratory $(36,37)$.

Sixty-eight neonatal rats, originating from nine different litters, were divided randomly into four groups: Group $1(\mathrm{C}+\mathrm{NS}, n=12)$, mother-fed and gavaged with $0.1 \mathrm{ml}$ normal saline daily. Group 2 $(\mathrm{C}+\mathrm{hBD} 3, n=12)$, mother-fed, hBD3 $(100 \mu \mathrm{g} / \mathrm{kg}$ with a volume of $0.1 \mathrm{ml}$ ) administrated. Group 3 (NEC+NS, $n=20)$, NEC-induced and treated with $0.1 \mathrm{ml}$ NS before asphyxia stress. Group 4 (NEC+hBD3, $n=24)$, NEC-induced and $100 \mu \mathrm{g} / \mathrm{kg} \mathrm{hBD} 3$ administrated. Animals were sacrificed via cervical dislocation upon the development of NEC clinical signs (abdominal distension, discolored abdominal walls, or bloody stools) or at the end of the experiment on day 4 .

After the killing, the intestine was removed and macroscopically evaluated for typical signs of NEC. Hematoxylin and eosin (H\&E) staining was performed. Pathological changes were scored blindly by an experienced pathologist (X.W.) using a previously published NEC scoring system $(31,36,37)$. Tissues with scores 2 or higher were defined as NEC positive. The rest of the ileum was stored for protein and RNA analysis. The small intestine and colon of adult SpragueDawley rats were obtained and prepared as indicated above.

\section{Immunostaining, Real-Time PCR, Western Blot Analysis, and ELISA}

Immunostaining for Caco-2 cells and rat intestine was performed as previously described $(2,37)$. The mRNA levels were detected in triplicate using SYBR Green, two-step RT-PCR (TakaRa, Dalian, China). Primer sequences are listed in Table 4. Electrophoresis of hBD3 was performed on a $16.5 \%$ Tris-Tricine gel under reduced condition (50 $\mathrm{mmol} / \mathrm{l}$ dithiothreitol). The gel was then stained with Coomassie dye. SDS-PAGE was also performed as described (2). DAO in the serum and TNF- $\alpha$ in the serum or supernatants were determined using rat DAO and TNF- $\alpha$ ELISA kit (R\&D systems), respectively.

\section{Statistical Analysis}

Statistical analysis was performed using the SPSS 17.0 software package. The incidence of NEC was compared using $\chi^{2}$ test. Survival time was analyzed by Kaplan-Meier analysis (with log-rank test). The severity of NEC was calculated using Mann-Whitney $U$-test. Other results were expressed as mean $\pm \mathrm{SD}$. The differences among four groups were detected by one-way analysis of variance and StudentsNewman-Keuls post hoc test. Difference was considered to be significant when $P<0.05$.

\section{STATEMENT OF FINANCIAL SUPPORT}

This work was supported by grants from National Nature Science Foundation of China (81370743), Shanghai Science and Technology Commission (124119a6500), Shanghai Key Laboratory of Pediatric Gastroenterology and Nutrition (11DZ2260500), and Doctorial Innovation Foundation of Shanghai Jiao Tong University School of Medicine (BXJ201241).

Disclosure: The authors declare no conflict of interest.

\section{REFERENCES}

1. Neu J, Walker WA. Necrotizing enterocolitis. N Engl J Med 2011;364:25564.

2. Sodhi CP, Shi XH, Richardson WM, et al. Toll-like receptor-4 inhibits enterocyte proliferation via impaired beta-catenin signaling in necrotizing enterocolitis. Gastroenterology 2010;138:185-96.

3. Hackam DJ, Good M, Sodhi CP. Mechanisms of gut barrier failure in the pathogenesis of necrotizing enterocolitis: Toll-like receptors throw the switch. Semin Pediatr Surg 2013;22:76-82.

4. Semple F, Dorin JR. ß-Defensins: multifunctional modulators of infection, inflammation and more? J Innate Immun 2012;4:337-48.

5. Meisch JP, Vogel RM, Schlatzer DM, Li X, Chance MR, Levine AD. Human ß-defensin 3 induces STAT1 phosphorylation, tyrosine phosphatase activity, and cytokine synthesis in T cells. J Leukoc Biol 2013;94:459-71.

6. Jenke AC, Zilbauer M, Postberg J, Wirth S. Human B-defensin 2 expression in ELBW infants with severe necrotizing enterocolitis. Pediatr Res 2012;72:513-20.

7. Armogida SA, Yannaras NM, Melton AL, Srivastava MD. Identification and quantification of innate immune system mediators in human breast milk. Allergy Asthma Proc 2004;25:297-304.

8. Seo EJ, Weibel S, Wehkamp J, Oelschlaeger TA. Construction of recombinant E. coli Nissle $1917(\mathrm{EcN})$ strains for the expression and secretion of defensins. Int J Med Microbiol 2012;302:276-87.

9. Underwood MA, Kananurak A, Coursodon CF, et al. Bifidobacterium bifidum in a rat model of necrotizing enterocolitis: antimicrobial peptide and protein responses. Pediatr Res 2012;71:546-51.

10. Dwinell MB, Eckmann L, Leopard JD, Varki NM, Kagnoff MF. Chemokine receptor expression by human intestinal epithelial cells. Gastroenterology 1999;117:359-67. 
11. Izadpanah A, Dwinell MB, Eckmann L, Varki NM, Kagnoff MF. Regulated MIP-3alpha/CCL20 production by human intestinal epithelium: mechanism for modulating mucosal immunity. Am J Physiol Gastrointest Liver Physiol 2001;280:G710-9.

12. Schutyser E, Struyf S, Van Damme J. The CC chemokine CCL20 and its receptor CCR6. Cytokine Growth Factor Rev 2003;14:409-26.

13. Hirsch T, Spielmann M, Zuhaili B, et al. Human beta-defensin-3 promotes wound healing in infected diabetic wounds. J Gene Med 2009;11:220-8.

14. Mammen JM, Matthews JB. Mucosal repair in the gastrointestinal tract. Crit Care Med 2003;31(8 Suppl):S532-7.

15. Wu Z, Hoover DM, Yang D, et al. Engineering disulfide bridges to dissect antimicrobial and chemotactic activities of human beta-defensin 3. Proc Natl Acad Sci USA 2003;100:8880-5.

16. Vongsa RA, Zimmerman NP, Dwinell MB. CCR6 regulation of the actin cytoskeleton orchestrates human beta defensin-2- and CCL20-mediated restitution of colonic epithelial cells. J Biol Chem 2009;284:10034-45.

17. Chaturvedi LS, Marsh HM, Basson MD. Role of RhoA and its effectors ROCK and mDial in the modulation of deformation-induced FAK, ERK, p38, and MLC motogenic signals in human Caco-2 intestinal epithelial cells. Am J Physiol, Cell Physiol 2011;301:C1224-38.

18. Totsukawa G, Yamakita Y, Yamashiro S, Hartshorne DJ, Sasaki Y, Matsumura F. Distinct roles of ROCK (Rho-kinase) and MLCK in spatial regulation of MLC phosphorylation for assembly of stress fibers and focal adhesions in 3T3 fibroblasts. J Cell Biol 2000;150:797-806.

19. De Plaen IG. Inflammatory signaling in necrotizing enterocolitis. Clin Perinatol 2013;40:109-24.

20. Luk GD, Bayless TM, Baylin SB. Diamine oxidase (histaminase). A circulating marker for rat intestinal mucosal maturation and integrity. J Clin Invest 1980;66:66-70.

21. Pérez-Cañadillas JM, Zaballos A, Gutiérrez J, et al. NMR solution structure of murine CCL20/MIP-3alpha, a chemokine that specifically chemoattracts immature dendritic cells and lymphocytes through its highly specific interaction with the beta-chemokine receptor CCR6. J Biol Chem 2001;276:28372-9.

22. Schibli DJ, Hunter HN, Aseyev V, et al. The solution structures of the human beta-defensins lead to a better understanding of the potent bactericidal activity of HBD3 against Staphylococcus aureus. J Biol Chem 2002;277:8279-89.

23. Niyonsaba F, Ushio H, Nakano N, et al. Antimicrobial peptides human beta-defensins stimulate epidermal keratinocyte migration, proliferation and production of proinflammatory cytokines and chemokines. J Invest Dermatol 2007;127:594-604
24. Funderburg NT, Jadlowsky JK, Lederman MM, Feng Z, Weinberg A, Sieg SF. The Toll-like receptor $1 \frac{1}{2}$ agonists $\operatorname{Pam}(3) \operatorname{CSK}(4)$ and human B-defensin-3 differentially induce interleukin-10 and nuclear factor-?B signalling patterns in human monocytes. Immunology 2011;134:151-60.

25. Wilson CL, Ouellette AJ, Satchell DP, et al. Regulation of intestinal alphadefensin activation by the metalloproteinase matrilysin in innate host defense. Science 1999;286:113-7.

26. Semple F, Webb S, Li HN, et al. Human beta-defensin 3 has immunosuppressive activity in vitro and in vivo. Eur J Immunol 2010;40:1073-8.

27. Semple F, MacPherson H, Webb S, et al. Human B-defensin 3 affects the activity of pro-inflammatory pathways associated with MyD88 and TRIF. Eur J Immunol 2011;41:3291-300.

28. Zilbauer M, Jenke A, Wenzel G, et al. Expression of human beta-defensins in children with chronic inflammatory bowel disease. PLoS ONE 2010;5:e15389.

29. Meisch JP, Nishimura M, Vogel RM, et al. Human B-defensin 3 peptide is increased and redistributed in Crohn's ileitis. Inflamm Bowel Dis 2013;19:942-53.

30. Salzman NH, Hung K, Haribhai D, et al. Enteric defensins are essential regulators of intestinal microbial ecology. Nat Immunol 2010;11:76-83.

31. Feng J, Besner GE. Heparin-binding epidermal growth factor-like growth factor promotes enterocyte migration and proliferation in neonatal rats with necrotizing enterocolitis. J Pediatr Surg 2007;42:214-20.

32. Rahim S, Üren A. A real-time electrical impedance based technique to measure invasion of endothelial cell monolayer by cancer cells. J Vis Exp 2011;50:e2792.

33. van Gils JM, Derby MC, Fernandes LR, et al. The neuroimmune guidance cue netrin-1 promotes atherosclerosis by inhibiting the emigration of macrophages from plaques. Nat Immunol 2012;13:136-43.

34. Houle VM, Park YK, Laswell SC, Freund GG, Dudley MA, Donovan SM. Investigation of three doses of oral insulin-like growth factor-I on jejunal lactase phlorizin hydrolase activity and gene expression and enterocyte proliferation and migration in piglets. Pediatr Res 2000;48:497-503.

35. Neal MD, Sodhi CP, Dyer M, et al. A critical role for TLR4 induction of autophagy in the regulation of enterocyte migration and the pathogenesis of necrotizing enterocolitis. J Immunol 2013;190:3541-51.

36. Caplan MS, Hedlund E, Adler L, Hsueh W. Role of asphyxia and feeding in a neonatal rat model of necrotizing enterocolitis. Pediatr Pathol 1994;14:1017-28.

37. Sheng Q, Lv Z, Cai W, Song H, Qian L, Wang X. Protective effects of hydrogen-rich saline on necrotizing enterocolitis in neonatal rats. J Pediatr Surg 2013;48:1697-706. 